\title{
How to Improve the Effectiveness of Caries-Preventive Programs Based on Fluoride
}

\author{
H. Hausen \\ Institute of Dentistry, University of Oulu, Oulu, Finland
}

\author{
Key Words \\ Dental caries · Effectiveness, program · Fluoride . \\ Prevention
}

\begin{abstract}
During recent years, an increasing number of reports have been published in which the observed caries-preventive effect of fluoride has been lower than could have been expected on the basis of the earlier literature. The current low levels of caries occurrence and the widespread use of fluoridated toothpastes as well as other fluoride products and methods have been suggested as reasons for the reduced relative effect of fluoride from any single source. Theoretically, one can improve the effectiveness of fluoride in caries-preventive programs by using measures that are more effective than the previous ones and still safe and feasible in everyday conditions. Another possibility is to direct fluoride-based prevention to high caries risk susceptible individuals who are most likely to benefit from it. Thirdly, one can enhance the intensity of existing fluoride prevention by increasing the frequency of applications, but this is of course worthwhile only if the recipients are lacking sufficient exposure to fluoride. In theory, people themselves could easily take care of their adequate fluoride supply by using fluoride toothpastes and/or other home use
\end{abstract}

products frequently enough to maintain a sufficient salivary fluoride concentration at all times. Many people are unwilling to adopt healthy lifestyles, however, and therefore caries-preventive programs will remain necessary for the foreseeable future. Fluoride is the backbone of all such programs. Since conditions strongly determine the usefulness of caries prevention including different fluoride regimes, more research is still needed to monitor the effectiveness of caries-preventive programs and their components in variable conditions of today and tomorrow.

Copyright $(\subset) 2004$ S. Karger AG, Basel

During recent years, an increasing number of reports have been published in which the observed caries-preventive effect of fluoride has been lower than could have been expected on the basis of the earlier literature. This is true for both systemic and topical methods such as water fluoridation [Parviainen et al., 1985], fluoridated school milk [Ketley et al., 2003], fluoride mouthrinses [Stamm et al., 1984] and professional applications of topical fluoride [Schuller and Kalsbeek, 2003] including fluoride varnish applications [Hausen et al., 2000]. The current low levels of caries occurrence and the widespread use of fluoridated toothpastes as well as other fluoride products and methods have been suggested as reasons for the reduced rela-

\begin{tabular}{ll}
\hline KARGER & ( ) 2004 S. Karger AG, Basel \\
0008-6568/04/0383-0263\$21.00/0 \\
$\begin{array}{l}\text { Fax +4161306 1234 } \\
\begin{array}{l}\text { E-Mail karger@karger.ch } \\
\text { www.karger.com }\end{array}\end{array}$ & $\begin{array}{l}\text { Accessible online at: } \\
\text { www.karger.com/cre }\end{array}$
\end{tabular}

Hannu Hausen

Institute of Dentistry, University of Oulu

PO Box 5281

FI-90014 Oulu (Finland)

Tel. +358 8537 5582, Fax +358 8537 5560, E-Mail Hannu.Hausen@oulu.fi 
tive effect of water fluoridation [Horowitz, 1996]. In the same way, the fact that people are today commonly exposed to fluoride from multiple sources is likely to dilute the effect of fluoride from any single source.

The moderate usefulness of added fluoride exposure at the population level today may also be due to the fact that individually applicable fluoride regimes are most likely to reach people who least need them. The individuals whose dental health-related lifestyles are most unfavorable and who are not visiting a dentist regularly are likely to be least exposed to fluoride and it is not easy to provide them with any individual protection against caries. The advantage of community water fluoridation is that it reaches even the least advantaged segments of the population. If the risk for caries is high, however, water fluoridation alone cannot provide full protection against the onset of cavities.

Despite the generally low average DMF figures in the Western industrial countries today, dental decay is still far from being a rare disease. Roughly half of the 12-year-olds in two Finnish cities had at least one DMF surface in the 1990s [Seppä et al., 2000] and, at the same time, almost half of the participants of a caries study in Vantaa, Finland, who had no DMF surfaces at the age of 12, developed at least one carious lesion by the age of 15 years with the maximum DMF increment being twelve surfaces within a period of 3 years [Hausen et al., 2000]. It seems to be possible to introduce caries activity into a previously healthy dentition at any age. For a minority of the contemporary Western people, caries still is a true problem [Kaste et al., 1996; Seppä et al., 2000]. Recent reports reveal that the long-time declining trend in the occurrence of dental caries has leveled off at least in some countries [Poulsen and Scheutz, 1999; Haugejorden and Birkeland, 2002]. Consequently, there is still ample need for more effective measures of controlling caries.

Efficacy, effectiveness and efficiency reveal different aspects of the effect of an intervention. This nomenclature was originally developed by Cochrane [1972]. Efficacy is the extent to which a measure produces a beneficial effect under ideal conditions, while effectiveness deals with the corresponding extent under everyday circumstances in the field. Efficiency considers the effect achieved in relation to the resources expended [Last, 2001]. These concepts constitute a hierarchy. If efficacy is lacking, there cannot be any effectiveness, which in turn is a basic requirement for efficiency. However easily and cheaply a measure can be applied, the application does not pay off if there is no beneficial effect.
In the 1960s, Schwartz and Lelouch [1967] introduced the concepts of explanatory and pragmatic trials. The evidence for the effect of fluoride preventives usually stems from explanatory clinical trials that aim at assessing the efficacy of the measure under study. The idea of an explanatory clinical trial is to give the measure a chance to show its effect under the most favorable conditions that are conceivable. Whenever possible, efficacy is assessed among carefully selected, motivated and compliant randomly assigned subjects who are not exposed to any factors that could mask or dilute the beneficial effect of the studied intervention. Especially in the early explanatory clinical trials, participants who dropped out of the study or changed groups were often excluded from the statistical analyses. Thereby the internal validity of the trial was maximized, but at the expense of reduced external validity, i.e. the generalizability of the results. To be useful for the practitioner, the results also need to be applicable to real-world situations. Unfortunately, there tends to be an inverse association between the internal validity of clinical trials and the generalizability of their results to the everyday practice of health care.

Many reasons limit the value of the results from purely explanatory clinical trials for designing caries-preventive programs to be implemented in the field under everyday conditions. First, no strict entry criteria are applicable in everyday life where the whole range of manifestations of both dental caries and its determinants are represented and where the compliance of people may be highly variable. Second, the beneficial effect of caries-preventive efforts is known to be strongly dependent on the characteristics of the target population, such as the level of caries occurrence and factors determining the rate of onset and progression of carious lesions. Third, caries-preventive programs often comprise multiple preventive measures for which it is important to know whether each of them retains its effect when applied together with the others.

Pragmatic trials aim at finding out the effectiveness of an individual measure or a program including multiple approaches, which means that they focus on the usefulness of the intervention in everyday conditions [Schwartz and Lelouch, 1967; Roland and Torgerson, 1998]. Theoretically, pragmatic trials that are well designed and conducted provide the practitioners with the best possible evidence that is needed for planning and implementing caries prevention in the field. It is somewhat surprising that even though the idea of a pragmatic clinical trial was introduced to the dental research community already in the middle 1970s [O'Mullane, 1976], the number of such trials has been limited. Moreover, even the results of prag- 
matic clinical trials cannot be extrapolated to circumstances that are different from those in which the intervention was studied. In designing contemporary clinical trials, procedures that improve the generalizability of the results are fortunately often preferred even in cases where the planned trial is not explicitly pragmatic.

To summarize the effects of various fluoride-based interventions, several well-conducted systematic reviews have been published recently [McDonagh et al., 2000; Marinho et al., 2003a, b, e], and there are quite a few under preparation [Marinho et al., 2003c, d, f, g; Yeung and Tickle, 2003]. A considerable part of the original research included in these reviews was conducted a long time ago in conditions that are different from those of today. Therefore, the value of their results for reducing uncertainties related to upcoming decisions on the policies of today and tomorrow should be considered carefully in each particular case. The conditions that determine the occurrence of caries in a population can change rapidly, resulting in both steep increases and decreases of caries frequency in different parts of the world. Consequently, it is not easy to find from the literature timely and accurate information that would be applicable as such to the everyday conditions of a particular setting. This is especially true for the effectiveness of individual fluoride measures in programs that use multiple approaches to control caries. Extrapolation of information related to efficiency is even more problematic since costs may vary between settings. Consequently, preventive programs are often run without an exact idea of their expected usefulness.

Theoretically, one can improve the effectiveness of preventive programs by including in them components that are more effective than the previous ones and still safe and feasible in everyday conditions. If the costs do not rise, even the efficiency will improve. As for fluoride, improvement could possibly be achieved by using novel fluoride formulations or using the existing ones in more efficacious forms like stronger concentrations. Another possibility is to direct fluoride-based prevention to high caries risk susceptible individuals who are most likely to benefit from it. Thirdly, one can enhance the intensity of existing fluoride prevention by increasing the frequency of applications, but this is only worthwhile if the recipients are lacking sufficient exposure to fluoride.

At present, none of the above lines of action is likely to bring about a dramatic breakthrough. Much effort has been and is currently made to find out whether novel formulations could make it possible to increase the effect of fluoride in caries prevention. Titanium tetrafluoride makes an example of a formulation regarding which the results of several studies look promising [Reed and Bibby, 1976; Derand et al., 1989; Skartveit et al., 1991; de Oliveira and Cordeiro, 1995; Buyukyilmaz et al., 1997; Tezel et al., 2002]. Until now, however, there is no evidence stemming from large-scale randomized clinical trials on its applicability and superiority in everyday life. For fluoride toothpastes, there is evidence that the caries-preventive effect increases along with an increasing fluoride concentration [Marks et al., 1992]. So far, this observation has not been fully exploited. Overall, however, it can be concluded that there are no new methods of using the fluoride at hand, whose effect would be substantially higher than that of the preventives in general use today.

Targeting fluoride prevention to high-risk individuals is problematic since it is difficult to distinguish between individuals who will and who will not develop cavities in the future. In spite of the poor accuracy of the currently available methods for assessing caries risk, the costs of screening the supposed high-risk individuals can be substantial. In addition, there is no good evidence of the successfulness of the high-risk approach in controlling caries [Hausen et al., 2000]. By using the directed population approach in which prevention is targeted to high-risk groups rather than individuals, one can avoid the costs of screening individuals, but even for this approach the rate of success still remains unclear.

Increasing the frequency of fluoride applications may lead to somewhat better effectiveness, but in many populations today this will most likely happen at the cost of reduced efficiency, at least when the applications are performed at dental clinics. If the increased frequency of fluoride exposure can be achieved with little additional cost, however, this possibility is worth considering. Theoretically, people themselves could easily take care of their adequate fluoride supply by using fluoride toothpastes and other home use products frequently enough to maintain a sufficient salivary fluoride concentration at all times. A considerable part of European children brush their teeth only once a day or less often [Kuusela et al., 1997]. The concept of the reversed prevention paradox [Rose, 1992] includes the idea that when many people each receive a little benefit, the total benefit may be large. Accordingly, a considerable reduction in the occurrence of caries could possibly be achieved with little cost if everybody started using fluoridated toothpaste and/or other fluoride products suited for daily use twice a day or, if specially needed, even more often. There is recent evidence from the UK that caries among 5- to 6-year-olds could be reduced simply by providing free toothpaste with an adequate fluoride concentration [Davies et al., 2002]. 
It is important to realize that people themselves can do a lot for maintaining good oral health. Many oral health care professionals, however, do not believe in the possibility of introducing changes in the lifestyles that affect the onset and progression of cavities among their patients. This is understandable since patient compliance does vary, and favorable changes seldom appear immediately. Therefore, it is not uncommon that patients are not given advice on proper self-care when they visit dental clinics. At least in Finland, the fact that caries was declining rapidly in the 1970s and 1980s at the same time as the numbers of professional preventive measures at dental clinics were increasing sharply may also have contributed to the overestimation of the potential of the oral health care system and to the underestimation of the resources of people themselves in promoting and maintaining oral health. Everyone should know, however, that for most individuals whose general health and oral conditions are not impaired, observing moderate snacking habits and using fluoridated toothpaste twice a day is probably sufficient to prevent cavities from occurring. If a caries-preventive program is run among such people, its effectiveness and efficiency are likely to be very low. Many people are unwilling to adopt healthy lifestyles, however, and therefore caries-preventive programs will remain necessary for the foreseeable future. Fluoride is the backbone of all such programs. If the oral conditions are impaired and/or the patient's lifestyle strongly favors the onset and progression of carious lesions, however, even an ideal fluoride regime may not be sufficient to prevent cavities from developing. Consequently, when designing programs to control caries it is essential to appreciate the multifactorial etiology of dental caries and not to rely merely on measures increasing the resistance of teeth.

Recent literature has revealed instances where a considerable reduction of the level of preventive efforts has not been followed by an increase in caries frequency [Seppä et al., 2000] and vice versa [Hausen et al., 2000]. This must have been due to the fact that the studied preventive methods, that had proved to be effective elsewhere, were not effective and efficient in those particular settings. Since conditions strongly determine the usefulness of caries prevention including different fluoride regimes, more research is still needed to monitor the effectiveness of caries-preventive programs and their components in variable conditions of today and tomorrow.

\section{References}

Buyukyilmaz T, Øgaard B, Duschner H, Ruben J, Arends $\mathrm{J}$ : The caries-preventive effect of titanium tetrafluoride on root surfaces in situ as evaluated by microradiography and confocal laser scanning microscopy. Adv Dent Res 1997; 11:448-452.

Cochrane AL: Effectiveness and Efficiency: Random Reflections on Health Services. London, The Nuffield Provincial Hospitals Trust, 1972.

Davies GM, Worthington HV, Ellwood RP, Bentley EM, Blinkhorn AS, Taylor GO, Davies RM: A randomised controlled trial of the effectiveness of providing free fluoride toothpaste from the age of 12 months on reducing caries in 5-6 year old children. Community Dent Health 2002;19:131-136.

Derand T, Lodding A, Petersson LG: Effect of topical $\mathrm{F}^{-}$solutions on caries-like lesions in root surfaces. Caries Res 1989;23:135-140.

Haugejorden O, Birkeland JM: Evidence for reversal of the caries decline among Norwegian children. Int J Paediatr Dent 2002;12:306-315.

Hausen H, Kärkkäinen S, Seppä L: Application of the high-risk strategy to control dental caries. Community Dent Oral Epidemiol 2000;28:2634.

Horowitz HS: The effectiveness of community water fluoridation in the United States. J Public Health Dent 1996;56:253-258.
Kaste LM, Selwitz RH, Oldakowski RJ, Burnelle JA, Winn DM, Brown LJ: Coronal caries in the primary and permanent dentition of children and adolescents 1-17 years of age: United States, 1988-1991. J Dent Res 1996;75(special issue):631-641.

Ketley CE, West JL, Lennon MA: The use of school milk as a vehicle for fluoride in Knowsley, UK: An evaluation of effectiveness. Community Dent Health 2003;20:83-88.

Kuusela S, Honkala E, Kannas L, Tynjälä J, Wold B: Oral hygiene habits of 11-year-old schoolchildren in 22 European countries and Canada in 1993/1994. J Dent Res 1997;76:1602-1609.

Last JM (ed): A Dictionary of Epidemiology, ed 4. Oxford, Oxford University Press, 2001.

McDonagh M, Whiting P, Bradley M, Cooper J, Sutton A, Chestnutt I, Misso K, Wilson P, Treasure E, Kleijnen J: A Systematic Review of Public Water Fluoridation. York, NHS Centre for Reviews and Dissemination, 2000.

Marinho VCC, Higgins JPT, Logan S, Sheiham A: Fluoride gels for preventing dental caries in children and adolescents. Cochrane Database Syst Rev 2003a.

Marinho VCC, Higgins JPT, Logan S, Sheiham A: Fluoride varnishes for preventing dental caries in children and adolescents. Cochrane Database Syst Rev 2003b.
Marinho VCC, Higgins JPT, Sheiham A, Logan S: Combinations of topical fluorides (varnishes, gels, rinses, toothpastes) versus one topical fluoride for preventing dental caries in children and adolescents. Cochrane Database Syst Rev 2003c.

Marinho VCC, Higgins JPT, Sheiham A, Logan S: Fluoride rinses for preventing dental caries in children and adolescents. Cochrane Database Syst Rev 2003d.

Marinho VCC, Higgins JPT, Sheiham A, Logan S: Fluoride toothpastes for preventing dental caries in children and adolescents. Cochrane Database Syst Rev 2003e; 1:CD002278.

Marinho VCC, Higgins JPT, Sheiham A, Logan S: One topical fluoride (varnishes, or gels, or rinses, or toothpastes) versus another for preventing dental caries in children and adolescents. Cochrane Database Syst Rev $2003 \mathrm{f}$.

Marinho VCC, Sheiham A, Logan S, Higgins JPT: Topical fluoride (toothpastes, mouthrinses, gels or varnishes) for preventing dental caries in children and adolescents. Cochrane Database Syst Rev 2003g.

Marks RG, D’Agostino R, Moorhead JE, Conti AJ, Cancro L: A fluoride dose-response evaluation in an anticaries clinical trial. J Dent Res 1992; 71:1286-1291. 
de Oliveira, Cordeiro JG: The effect of various fluoride compounds on the development of experimental root surface caries in hamsters. Bull Tokyo Med Dent Univ 1995;42:105-116.

O'Mullane DM: Efficiency in clinical trials of caries preventive agents and methods. Community Dent Oral Epidemiol 1976;4:190-194.

Parviainen K, Ainamo J, Nordling H: Changes in oral health from 1973 to 1982 of 13-15-yearold schoolchildren residing in three different fluoride areas in Finland. J Dent Res 1985;64: 1253-1256.

Poulsen S, Scheutz F: Dental caries in Danish children and adolescents 1988-1997. Community Dent Health 1999;16:166-170.
Reed AJ, Bibby BG: Preliminary report on effect of topical applications of titanium tetrafluoride on dental caries. J Dent Res 1976;55:357-358.

Roland M, Torgerson DJ: What are pragmatic trials? BMJ 1998;316:285.

Rose G: The Strategy of Preventive Medicine. Oxford, Oxford University Press, 1992.

Schuller AA, Kalsbeek H: Effect of the routine professional application of topical fluoride on caries and treatment experience in adolescents of low socio-economic status in the Netherlands. Caries Res 2003;37:172-177.

Schwartz D, Lelouch J: Explanatory and pragmatic attitudes in therapeutic trials. J Chronic Dis 1967;20:637-648.

Seppä L, Kärkkäinen S, Hausen H: Caries trends 1992-1998 in two low-fluoride Finnish towns formerly with and without fluoridation. Caries Res 2000;34:462-468.
Skartveit L, Spak CJ, Tveit AB, Selvig KA: Cariesinhibitory effect of titanium tetrafluoride in rats. Acta Odontol Scand 1991;49:85-88.

Stamm JW, Bohannan HM, Graves RC, Disney JA: The efficiency of caries prevention with weekly fluoride mouthrinses. J Dent Educ 1984;48:617-626.

Tezel H, Ergucu Z, Onal B: Effects of topical fluoride agents on artificial enamel lesion formation in vitro. Quintessence Int 2002;33:347352.

Yeung CA, Tickle M: Fluoridated milk for preventing dental caries in children and adolescents. Cochrane Database Syst Rev 2003. 